\title{
Redesigning the Relationship between Government and Civil Society: An Investigation of Emerging Models of Networked Democracy in Brazil
}

\author{
Eduardo Henrique Diniz and Manuella Maia Ribeiro \\ Escola de Administração de Empresas de São Paulo, Fundação Getulio Vargas \\ São Paulo, Brazil \\ eduardo.diniz@fgv.br, maiamanuella@gmail.com
}

\begin{abstract}
The concept of networked public sphere [3] modifies the original Habermasian definition of public sphere by considering the dissemination of new interactive technologies that potentially allow new relations between civil society and government. The objective of this paper is to investigate the emergence of the networked public sphere based on the in-depth study of two Brazilian cities that have created conditions for their citizens to influence public policies through the use of Internet-based virtual platforms. To develop our study we adapt the method for analyzing political participation called democracy cube [13] that considers mechanisms of participation along three dimensions: a) who participates, b) how participants communicate with each other and make decisions, and c) how these decisions relate to political action and public policies. Our investigation shows that citizens of the two cities presented in this study use the virtual platform to engage in lively discussions and exchange of information as a way to propose and implement new public policies that are eventually adopted by their city governments. We conclude that, albeit at an early stage, the use of virtual platforms to share opinions on topics that citizens want to be recognized helps to mobilize public opinion and participation and influence the opinion of local public officials on policy implementations.
\end{abstract}

Keywords: city government, e-democracy, networked civil sphere, public participation, virtual platform.

\section{Introduction}

More than 1,000 reports of irregularities were submitted by citizens in a platform created by volunteers to monitor the Brazilian elections of October 2010. Since the Chinese government refused to disclose the names of the victims of an earthquake in 2008, citizens struggle to ensure transparency through a website created to investigate the identity of killed students. In Jundiaí, Brazil, a city of 370,000 inhabitants $60 \mathrm{~km}$ from São Paulo, a social network discussed and approved citizen initiatives to guarantee funding for the municipal government to build $25 \mathrm{~km}$ of bike lanes in the city. In India, a collaborative website was created to receive complaints of bribing to public officials. 
These are four examples of Internet use by civil society available on the Technology for Transparency Network website, an initiative created by the non-governmental organization (NGO) Global Voices to map experiences of how information and communication technologies (ICTs) are being used by citizens around the world to promote transparency, accountability and civic engagement.

The potential of the Internet to impact the relationship between government and civil society is also being highlighted since several demonstrations in several Arab countries were driven by the innovative use of social network technologies, some with the power to overthrow governments. The force of this media was recognized by Hosni Mubarak's dictatorial government that blocked access to the Internet for five days, showing the importance of Internet in the Egyptian conflict [15].

On the one hand, despite the massive use of the Internet in those conflicts, sometimes presented as the "Twitter Revolution" or the "Facebook Revolution", there is still no consensus on the technology's role as a democratization tool, since it also can be used as a mechanism for monitoring citizens, spreading propaganda and sustaining authoritarian regimes [20]. On the other hand, if the Internet could not be promoted as a tool for revolution, tools for decentralized distribution of messages, such as "tweets", have clearly helped to mobilize protesters and attract more people to the streets [4].

As pointed by Foth et al. [11, p. x], "over the past decade, ubiquitous computing, social media, and mobile technologies have become integral parts of our social lives and work practices, as well as shaping the way we make sense of our cultures and engage as citizens". In whatever way they are used, ubiquitous ICTs redefine citizens' social network activities [18] and are among the challenges surrounding contemporary democracies, in particular the relationship between civil society and governments.

To explain the role of these new technologies for social activism, Benkler [3] extends the Habermasian definition of public sphere into a concept of networked public sphere. Originally defined as the space in which civil society asserts that public authorities will act in accordance with its expectations, for Habermas [14] the public sphere was dominated by mass media. In a networked society, the virtual space created by the dissemination of new interactive technologies potentially allows new relations between civil society and government.

This paper investigates ways that civil society through virtual platforms has influenced local governments. Based on the study of two cases in Brazilian municipalities, the paper addresses the following research question: How do virtual platforms supported by ICTs provide coordination and collaboration in order to make civil participation effective in influencing government policies?

\section{Theoretical Framework}

\subsection{Networked Public Sphere}

Since the emergence of the Internet and universal access to information, the idea of the free flow of information has led to a series of economic, political and cultural 
changes, with clear impacts for governments and civil society. In his concept of networked society, Castells [8] states that the more technology is being incorporated into society, the more a dependency on knowledge and information generated and enhanced by ICTs becomes part of the overall structure. As a corollary, the networked society changes crucial sources of domination and transformation of our society.

The networked and information-based society would foster the emergence of a participatory culture capable of accepting and maintaining multiple points of view. The promise of this networked democracy lies in encouraging broader participation and taking advantage of the collective wisdom and the perspectives of crowds [19].

The concept of web 2.0 emphasizes the development of a networked world through interactive platforms where users create content individually and collectively, sharing and updating information and knowledge using sophisticated, diverse devices and sharing tools, remixing and improving content created by each other [24]. In the same way, crowdsourcing government is a concept related to the networked society that focuses on impacts on government actions created by citizens' input generated from small individual contributions made by a large number of people [7].

ICTs' potential for provoking substantial changes in democracy and the public sphere is also highlighted by Benkler [3] with the concept of the networked public sphere. Benkler emphasizes the possibilities of citizens redesigning their relations with public administration by using new technology platforms, thereby making civil society more engaged and participative in its relationship with government as interactions and communication between them become more electronic and virtually-based.

Benkler's networked public sphere is based on the cooperative production that emerges with individual freedom and made feasible by the digital environment. The success of such cooperative production will rely both on the design of the digitally networked environment and the participatory involvement of the public. Considering design, Benkler states that being modular and maintaining the capacity to integrate fine-grained contributions must be part of the technical and organizational characteristics in virtual platforms for social participation. As the networked public sphere enables individuals and groups to play a role traditionally assigned to the mass-mediadominated public sphere, Benkler stresses its connections with the idea of public participation in the democratic process.

\section{2 e-Democracy}

For the concept of e-democracy, the part concerning the use of technology is somehow the easiest to understand. Just as there are different views on the meaning of democracy [27], [16], [10], there are many different understandings about what edemocracy could be. Definitions also vary, and include: electronic democracy [9], [17], [23], cyberdemocracy [25], [21], digital democracy [12] and virtual democracy [27], among others. Sometimes different terms are used simultaneously as synonyms.

For advocates of participatory democracy, e-democracy would be an attempt to practice democracy without limits of time, place or other physical conditions, using ICTs or other kinds of computer-mediated communication [27]. Nevertheless, to 
achieve democracy as "a system for making decisions about public affairs in which citizens are directly involved" ([16], p. 4) would necessitate transformations of representation and the role of actors and civil society organization [6]. However, since political dialogue aimed at solving collective problems will require a plurality of perspectives together with styles of speech and ways to express the particularity of social situations, the implementation of a technology platform for a constant decisionmaking process with citizens is still virtually impossible. Thus, the Internet has not changed representative structures to revolutionize political processes [9], [12].

Given the limits for implementing such a deliberative democracy model, the more inclusive concept of communicative democracy could be considered as an alternative [28]. In other words, "virtual public sphere as a civil conversation seems to be more feasible $[\ldots]$ than implementation of decision mechanisms about policies through the exercise of institutional power" ([22], p. 181) considered by the direct democracy.

Regardless of the different concepts of democracy, all of them include public participation and social control over government actions [5]. According to Fung [13], public participation must work in synergy with representation processes. This author presents a model known as democracy cube, and considers that mechanisms of participation vary along three dimensions: a) those who participate, b) how participants communicate with each other and make decisions, and c) how these decisions relate to political action and public policy.

Combined with the networked civil society as defined by Benkler, the democracy cube of Fung provides us with a useful framework to capture the perspective of civil society influencing government actions through the active use of a virtual platform. Benkler's model of networked civil society is divided into two levels, platform organization and public participation. In this study, we subdivide each of these levels: we deal with two dimensions for the platform organization - modularity and granularity - as defined by Benkler, and three dimensions of public participation - the democracy cube - as defined by Fung.

\section{$3 \quad$ Research Methods}

Our main goal is to understand how civil society could influence local governments through virtual platforms in Brazil.

The case studies presented in this paper are both intrinsic and instrumental [26]. They are intrinsic because the cases themselves are of interest, in all their particularity and ordinariness. They also are instrumental because we seek to advance the understanding of those particular cases to produce relevant and actionable knowledge that could be transferable to other similar contexts.

We defined two stages of research:

1. Investigation of the main characteristics of a Brazilian virtual platform created to provide a mechanism for the civil society to influence public policies, in line with the networked public sphere proposed by Benkler; 
2. Investigation of two cases of that use of the virtual platform by civil society discussed in the previous stage, adapting the democracy cube proposed by Fung to analyze political participation.

Thus, to answer the question of the paper, we use Benkler's concept of virtual platform for a networked public sphere combined with the democracy cube proposed by Fung.

\subsection{Understanding the Virtual Platform}

According to Benkler [3], collaborative production on the web is one of the most significant attributes allowed by new technologies. This collaborative or peerproduction process has been enabled through Internet-based coordination, where decisions arise from the free engagement and cooperation of the people who coalesce to create common value [19].

For Benkler, the success of the peer-production processes has been the adoption of architectures that have allowed people to pool such diverse efforts effectively. The core characteristics underlying the success of these enterprises are their modularity and their capacity to integrate many fine-grained contributions.

The platform to be investigated is Cidade Democrática, which has been chosen because of its representativeness for civil society to discuss causes, solutions and problems in different Brazilian cities. Cidade Democrática is constantly open to receive contributions from society, and has the explicit intention to influence government actions based on the requests and demands raised on its platform. It is also open to any citizen. Therefore, this initiative is related to the networked public sphere by allowing a space for the dissemination, debate, and expression of public opinion.

\subsection{Applying the Democracy Cube}

The three dimensions of participation from the democracy cube were investigated in two selected case studies, both using the same platform, Cidade Democrática, as the virtual infrastructure for citizens and organizations from the civil society to influence local government actions. The two cases are projects in cities located in São Paulo state: Jundiaí and Várzea Paulista. Both initiatives are being used by their respective local governments to define their public policies.

To develop the in-depth case of the two cities using the Cidade Democrática platform, data collection was performed through:

a) Structured observation of project websites of the two cities inside the platform;

b) Document analysis of civil society organizations available on the web, blogs posted by citizens in the platforms, media news and city administration documents related to the two projects;

c) Semi-structured interviews in person or through questionnaires via e-mail with two founders and managers of the Cidade Democrática platform, three citizens users of the platform, three members of civil society and eight city officials of the two cities investigated. All interviews were done between December 2011 and January 2012. 


\section{Cidade Democrática Platform}

Cidade Democrática was launched to the public in October 2009 and works as a social network platform designed for the discussion of city problems. Any citizen can post problems or solutions that matter to a specific region and can also comment on, support or discuss ideas posted by other citizens. Thus, this platform is a space on the Internet where Brazilians can publish and discuss problems and solutions for municipalities. Registered users can create different types of profiles that range from citizens to entities such as nongovernmental organizations and public officials. In February 2012 , there were 11,135 registered users, approximately $97 \%$ of whom are citizens.

The Digital Cities Program was created by Cidade Democrática in 2011 as an experiment aiming to create public agendas through collaboration between local governments and society. The two cases studied in this paper are part of Digital Cities program. The first case is a pilot project called "Cidadonos" ("City owners") and was held in the city of Jundiaí. The second was a competition called "Digital Várzea 2022" held by the city of Várzea Paulista.

\subsection{Cidadonos Project in Jundiaí}

The Cidadonos project emerged in 2011 from a competition created by the informal group named "Movimento Voto Consciente Jundiaî" (Conscientious Vote Jundiaí). It was created to encourage citizens to publish proposals and raise issues for the construction of a civic agenda in order to foster involvement in public policy issues and other matters of public interest.

The project was a competition which took place through a customized portal of the Cidade Democrática platform developed to reward the 12 best ideas and proposals that would make true the dreams of the population of the city of Jundiaí. Citizens, NGOs, schools, businesses and government stakeholders could participate by presenting their own ideas and voting on others' proposals, supporting the implementation of a better Jundiaí. The competition was open from April 15 to August 8, 2011.

Although the word "reward" was contained in the description of the competition, the winners did not win any cash or other kind of prize, but would have their proposals included in the agenda of the Movimento Voto Consciente Jundiaí and receive a certificate of participation. About 3,500 citizens took part in the contest and 12 proposals were chosen based on the list of supporters, and the number of comments and followers.

After the competition, in December 2011, the Movimento Voto Consciente Jundiaí started a new stage of engagement which was directed to announce the awarded proposals to local government, NGOs and local businesses in order to discuss ways to implement the successful ideas. Among the actions in this stage are: forwarding proposals to government officials, such as secretaries, mayors and state and federal deputies of the region and to civil society organizations and businesses, then inviting them to talk about how they could put these ideas into effect. 


\subsection{Várzea Digital 2022 Competition}

The Várzea Digital 2022 competition was held by the City Hall of Várzea Paulista and was one of the actions of the Plan 2022 launched in early 2011 by the city government. Organized by the Secretary of Social Development of the city, the competition is considered to be an instrument of participatory planning of the city government. The goal of the competition was to stimulate the digital participation of citizens, especially the young people, in public policy issues. It was a strategy of participation that complemented the traditional practices of government.

The competition lasted two months, from September 19 to November 20, 2011 and citizens, NGOs, local business, city officers, and politicians from Varzea Paulista could participate by presenting proposals and making comments. By registering on the Cidade Democrática platform, the eight proposals and issues with the most votes were selected to be presented at the City Conference, and were included in the Developing Plan of the city to be implemented by 2022 . Close to 600 citizens enrolled in the competition.

\section{$5 \quad$ Analysis of the Cases}

The analysis of the cases was divided in two parts:

- The structured observation of the Portal Cidade Democrática to analyze its type of relationship model in the networked public sphere;

- Two in-depth case studies (the municipalities of Jundiaí and Várzea Paulista in the State of São Paulo). The case studies helped to understand the institutional design of participation through the Internet using an adapted model of the democracy cube.

\subsection{Type of Relationship Model in the Networked Public Sphere}

Cidade Democrática is a platform for content creation by either the owners of the initiative or any other participant in the project, who are free to post comments, vote or follow any posted issue or proposal. This type of platform allows and encourages discussion and collaborative production between users. Its initiatives include the collaborative construction of bills and public policies, mashups or crowdsourcing, for example. The content of this kind of initiative depends on public participation. Examples of technological tools available are:

-Wiki: it allows the construction of collaborative texts. Its main feature is that anyone can easily add, delete or change any part of a published text [1];

- Social Networking: it allows people connected to these networks to interact with friends and contacts through sharing and discussing interests, ideas, events, activities and media [2].

At Cidade Democrática, the contributors point out problems or solutions to problems in their cities and / or regions. Citizens can also comment on, support and follow the 
contributions made by other users. It features profiles on social networks and allows sharing of content across these.

Considering the characteristics of the virtual platform as described by Benkler that are necessary to create an environment for the networked civil sphere, Cidade Democrática presents both the granularity and modularity capabilities. The granularity is expressed by the possibility of collecting contributions from the public as small as it is possible, allowing them to post new proposals, comment on those already available, or even just supporting (similar to the "like" tool in Facebook) or voting for proposals already posted by other participating citizens. The modularity feature is also very important and has allowed different projects in different cities to re-use the same capabilities developed for previous initiatives. This improves the platform power as it helps to create distributed knowledge about the platform usage that is very important to disseminate, and to consolidate the platform as a robust and easy-to-use environment. The very situation we are investigating here with two different initiatives in two different cities using the same platform, each for its own purposes, is a clear demonstration of the modularity capability of Cidade Democrática.

\subsection{Classification of Jundiaí and Várzea Paulista Initiatives in the Democracy Cube}

To better understand the democracy cube for the two investigated initiatives, we are going to analyze them answering the main questions proposed by Fung to frame the public participation process.

Who Participates? Initially, competitions were open to all residents in Jundiaí and Várzea Paulista, i.e., everyone could participate in offering proposals or issues, posting comments, or registering their support by following a proposal or issue.

However, as stated by Fung [13], to be open to the whole of society does not mean that everyone will participate and that all groups called to participate will be represented. Therefore these initiatives would be classified in the self-selection category, defined as one in which the selection process is open to the whole population, although only the people concerned with the debate will effectively participate.

In addition to online participation, mobilization workshops were provided to publicize the capabilities of Cidade Democrática's web tools in order to mobilize citizens and help them to post, comment on or support proposals or issues. Some actions taken to publicize Cidade Democrática's capabilities were lectures and workshops in private and public schools as well as in some civil society organizations and companies. The general public was also encouraged to participate through partnerships with radio stations, newspapers and local television. These actions were fruitful especially among young people, who were usually more familiar with new technologies although, in general, less close to the more traditional ways of participation.

Thus, among the categories presented by Fung, the selection of participants in the case studies could be considered as selective recruitment, i.e., despite participation 
being open to everyone, tools have been created to reach certain groups and stimulate them to participate.

How Do Participants Communicate and Make Decisions Together? In both cases, participants had to mobilize other users as much as possible, making them comment on or support their proposals, so the winning proposals would depend on the level of mobilization provoked by the group that presented them. Interviews with the winners showed that they employed the most diverse modes of communication with others about their proposals, varying from online to face-to-face.

To gather support, users could also expose their proposals through social networks, blogs, videos, and photos. Although there was intense use of a variety of strategies, the Cidade Democrática platform was a space of constant interaction and exchange of views. It consolidated discussion about the projects in the competition. Among the categories presented by Fung [13], we identify the mode of communication of the projects studied as those related to the development of citizen preferences.

On the one hand, as a collaboration and interaction platform, Cidade Democrática ensured that citizen users of the platform may disagree, exchange information, and propose new ways to implement their proposals, among others. On the other hand, that does not mean necessarily that potential participants use the discussion capability of the platform during the competitions. For instance, support which depended only on a single click by the citizen received more than twice as many comments. In those cases, there was no discussion. The citizen's preference was captured only by a single-click interaction with that specific proposal.

How Discussions Are Linked with Policy or Public Action? First of all, we need to point out the differences between the initiatives taking place in Jundiaí and in Várzea Paulista. While in Jundiaí the initiative was conducted by a civil society organization that had been operating since 2006 in the municipality, in Varzea Paulista the initiative was led by the city government. This difference is crucial in understanding the political actions subsequent to the digital debate in the virtual environment.

In Jundiaí, the category defined as communicative influence prevailed. In this type of participatory mechanism, influencing the state is related to the ability to change or mobilize public opinion. The Voto Consciente Movement had this role to exert pressure on the city government to implement policies in accordance with the proposed agenda that emerged from the citizen participation in the digital environment. In addition, the authors of the winning proposals stated that they plan to continue mobilizing public opinion to make the city government pay attention to their demands.

In the case of Várzea Paulista, since the initiative was conducted by the city government, winning proposals presented by the citizens became part of the municipal plan goals for the medium and long term. City Hall created a commission composed of representatives of civil society and government to monitor the implementation of the proposals, either in person or through the city web site. In this sense, this particular experience approaches the category of co-governance in which there is a partnership between citizens and government to develop strategies for public action. 


\section{Conclusions}

As a theoretical contribution, this article intends to test the concept of networked public sphere in relation to the use of new technologies that allow citizens to participate actively in the public sphere and thereby generate some kind of impact on society. Proposed by Benkler [3], the concept of networked public sphere modifies the original definition of public sphere developed by Habermas, and seeks new understandings about it from the possibilities presented by new Internet-related interactive technologies such as blogs, websites, and Twitter.

As a contribution to the practice of management, the article analyzes, through the study of two particular cases in Brazil, how citizens are engaging in the use of virtual platforms, how effective those platforms are in achieving their purposes, what are the main characteristics of those platforms, what are the main difficulties faced by citizens and managers to operate and use such platforms, and how government officials incorporate contributions coming from those platforms. Understanding the operations of those platforms, their main challenges and the effectiveness of each of the tools used, would be helpful to improve the platforms themselves and will provide additional knowledge to those interested in creating similar platforms in Brazil and possibly in other countries and contexts.

We conclude that, albeit in an early stage, the use of virtual platforms to share opinions on topics that citizens want government to recognize helps with mobilization and influences local public officials on policy implementations. Our investigation shows that citizens of the two Brazilian cities studied use the virtual platform to engage in lively discussion and exchange information as a way to propose and implement new public policies that are eventually adopted by their city governments.

\section{References}

1. Baltzersen, R.K.: Radical transparency: open access as a key in wiki pedagogy. Australasian Journal of Educational Technology 26(6), 791-809 (2010)

2. Bekri, D., Dunn, B., Oguzertem, I., Su, Y., Upret, S.: Harnessing Social Media Tools to Fight Corruption. Final project for degree at LSE Department of International Development, London (2011)

3. Benkler, Y.: The Wealth of Networks: How Social Production Transforms Markets and Freedom. Yale University Press, New Haven (2006)

4. Bertot, J.C., Jaeger, P.T., Grimes, J.M.: Using ICTs to create a culture of transparency: Egovernment and social media as openness and anti-corruption tools for societies. Government Information Quarterly 27(3), 264-271 (2010)

5. Bobbio, N.: O futuro da democracia; uma defesa das regras do jogo. Paz e Terra, Rio de Janeiro (1986)

6. Brelàz, G.: de: Advocacy das organizações da sociedade civil: um estudo comparativo entre Brasil e Estados Unidos. Masters dissertation, FGV (2007)

7. Brito, J.: Hack, Mash and Peer: crowdsourcing government transparency. Science and Technology Law Review 9, 119-157 (2008)

8. Castells, M.: A Sociedade em Rede. Paz e Terra, São Paulo (2008) 
9. Chadwick, A.: Bringing E-Democracy Back In. Social Science Computer Review 21(4), 443-455 (2003)

10. Dahlberg, L., Siapera, E.: Radical democracy and the Internet: Interrogating Theory and Practice. Palgrave Macmillan, London (2007)

11. Foth, M., Forlano, L., Satchell, C., Gibbs, M. (eds.): From social butterfly to engaged citizen: urban informatics, social media, ubiquitous computing, and mobile technology to support citizen engagement. MIT Press, Cambridge (2011)

12. Fuchs, C.: Internet and Society: social theory in the information age. Routledge, New York (2008)

13. Fung, A.: Varieties of participation in a complex governance. Public Administration Review (Special Issue), 66-75 (December 2006)

14. Habermas, J.: Mudança estrutural da esfera pública. Tempo Brasileiro, Rio de Janeiro (2003)

15. Harb, Z.: Arab revolutions and the social media effect. M/C Journal, 14(2) (2011),

http: / / journal.media-culture.org.au/index.php/

mcjournal/article/viewArticle/364

16. Held, D.: Models of Democracy. Polity Press, Cambridge (2006)

17. Keskinen, A.M.: Models for Interactive Decision Making. Electronic Journal of eGovernment 2(1), 55-64 (2004)

18. Kim, B.J., Adam, F.: Social Media, Social Design and Social Construction: Dialectic Approach for the Use of Social Media in the Public Sector. The International Journal of Technology, Knowledge and Society 7(3), 65-78 (2011)

19. Kostakis, V.: The Advent of Open Source Democracy and Wikipolitics. Human Technology 7(1), 9-29 (2011)

20. Kyriakopoulou, K.: Authoritarian states and internet social media: instruments of democratization or instruments of control? Human Affairs 21, 18-26 (2011)

21. Lévy, P.: Pela ciberdemocracia. In: Moraes, D. (org.) Por uma outra comunicação, pp. 367-384. Record, Rio de Janeiro (2003)

22. Marques, F.P.J.A.: Dimensões da ciberdemocracia: conceitos e experiências fundamentais. Master Dissertation, UFBA, Bahia (2004)

23. Peixoto, T., Wegenast, T.A.: Democracia eletrônica no Brasil e no mundo. Revista do Legislativo (2010)

24. Petrik, K.: Deliberation and Collaboration in the Policy Process: A Web 2.0 approach. Journal of E-democracy 2(1) (2010)

25. Poster, M.: Cyber Democracy: Internet and the Public Sphere. In: Porter, D. (ed.) Internet Culture. Routledge, New York (1995)

26. Stake, R.E.: Qualitative Case studies. In: Denzin, N.K., Lincoln, Y.S. (eds.) Handbook of Qualitative Research, pp. 435-466. Sage Publications, Thousand Oaks (2005)

27. Van Dijk, J.A.G.M.: Digital democracy: issues of theory and practice. Sage Publications (2000)

28. Young, I.: Comunicação e o outro, além da democracia deliberativa. In: Souza, J. (org.) Democracia Hoje. Editora da UnB, Brasília (2001) 